\title{
Evaluation of Anxiety of Dental Treatments Among Dental Students: A Questionnaire Based Survey
}

\author{
Nor Masitah Mohamed Shukri ${ }^{1}$, Dhanraj Ganapathy², Arthi B ${ }^{3}$ and Revathi Duraiswamy ${ }^{4}$ \\ ${ }^{1}$ Saveetha Dental College and Hospitals, Saveetha Institute of Medical \\ and Technical Sciences, Saveetha University, Chennai, India \\ ${ }^{2}$ Professor \& Head, Saveetha Dental College and Hospitals, Saveetha Institute of \\ Medical and Technical Sciences, Saveetha University, Chennai, India \\ ${ }^{3}$ Senior Lecturer, Department of Public Health Dentistry, Saveetha Dental College and Hospitals, \\ Saveetha Institute of Medical and Technical Sciences, Saveetha University, Chennai, India \\ ${ }^{4}$ Senior Lecturer, Department of Prosthodontics, Saveetha Dental College and Hospitals, \\ Saveetha Institute of Medical and Technical Sciences, Saveetha University, Chennai, India
}

\section{ABSTRACT}

Dental anxiety can be described as a feeling of fear of seeking dental treatment which is often reported worldwide and globally observed in every generation of population. This psychological feeling becomes a challenging factor encountered by most dental practitioners. Dental anxiety can lead to negative attitude from seeking dental treatment, especially in dental patients with prolonged periods of dental problems. Dental anxiety is developed through a period of time and therefore dental anxiety is likely to be related with multifactorial etiologies. Majority of dental and medical students reported with high levels of stress and anxiety and may experience adverse effects. The aim of this study is to determine the frequency of dental anxiety to perform dental procedures among dental students. This cross-sectional study was conducted from June 2019-March 2020 among dental students of Saveetha Dental College. Study questionnaire was conducted through Google Form application using the modified Moss and McManus (Moss and McManus, 1992) clinical anxiety questionnaire. It contained 13 questions from the original document in relation to the specific perceived sources of anxiety. The collected data was validated, tabulated and analysed with Statistical Package for Social Sciences for Windows, version 23.0 (SPSS Inc., Chicago, IL, USA) and results were obtained. Descriptive statistics (frequency distribution, percentage and mean value) and inferential statistics (chi-square test) were done. In the present study, majority of the students rated deficiencies and error during treatment as more anxiety provoking situations as compared to act of treatment situations. According to male students, the top clinical anxiety provoking situations were accidental pulpal exposure and extracting the wrong tooth. Females voted most for fracturing teeth and extracting the wrong tooth. Accidental pulpal exposure, fracturing teeth and using high speed hand piece significantly elevates anxiety levels in dental students

KEY WORDS: ANXIETY; FEAR; DENTAL STUDENTS; DENTAL TREATMENT; STRESS.

\section{ARTICLE INFORMATION}

*Corresponding Author: dhanraj@saveetha.com

Received 13th June 2020 Accepted after revision 4th August 2020

Print ISSN: 0974-6455 Online ISSN: 2321-4007 CODEN: BBRCBA

Thomson Reuters ISI Web of Science Clarivate Analytics USA and Crossref Indexed Journal

$$
\begin{aligned}
& \text { Clarivate } \\
& \text { Analytics }
\end{aligned}
$$




\section{INTRODUCTION}

Dental anxiety can be described as a feeling of fear that prevents an individual from receiving dental treatment. It is often reported worldwide and globally observed in every generation of population. The prevalence of dental anxiety among the general population reported is between 3.9 and 11\% (Vermaire et al., 2016). This psychological feeling becomes a challenging factor encountered by most dental practitioners. Dental anxiety can lead to negative attitude from seeking dental treatment, especially in dental patients with prolonged periods of dental problems. Consequently, it is considered as one of the reasons for dental neglect (Eli, 1993). Anxious and frightened dental patients will suffer themselves from dental diseases and complications because they simply cancel or delay their visit to dental clinics (Pohjola et al., 2009) ; (Kesim et al., 2012). The delay of dental treatment results in various irreversible diseases. Hence, people with dental anxiety are more unlikely to be able to maintain a good quality of life, in regards to their oral health status (Armfield, Stewart and Spencer, 2007).

Dental anxiety is not usually developed instantly at a time. Not every patient that had a painful and bitter experience of dental treatment will suffer dental anxiety. It is developed through a period of time and therefore dental anxiety is likely to be related with multifactorial etiologies. Previous studies reported three reliable factors of causing dental fear. The first contribution is the pattern of dental avoidance and probable anxiety, second is related to the specific dental stimuli and procedures and last factor is related to the psychological surrounding arousal during dental treatment (Kleinknecht et al., 1984). Specific stimuli include sight of needles during local anaesthetic injections, sharp dental instruments, characteristic smell of a dental clinic, noises from dental drills. There are three phenomena that are concerned with the development of dental fear; instinctive, dependent on maturation and development through social experiences (Hall and Edmondson, 1983).

Medicine and dentistry are viewed as stressful professions. Majority of dental and medical students reported with high levels of stress and anxiety and may experience adverse effects. Study on anxiety of clinical medical students reported by Moss and McManus showed half of the participants had moderate to severe anxiety states (Moss and McManus, 1992). According to Davidovich et al, a higher number of dental students elicited anxiety and stress during dental treatment when compared to experienced dentists (Davidovich et al., 2015). An online questionnaire conducted in University of Otago had revealed a high prevalence of detrimental emotions among fourth year dental and medical students. These findings of adverse mental stability reported by students is alarming and needs to be addressed. It is evident that most of the undergraduate students elicited stress and anxiety due to academic and emotional disturbances (Qamar, Khan and Bashir Kiani, 2015).
Previously our department has published extensive research on various aspects of prosthetic dentistry ('Evaluation of Corrosive Behavior of Four Nickelchromium Alloys in Artificial Saliva by Cyclic Polarization Test:An in vitro Study', 2017; Ganapathy, Kannan and Venugopalan, 2017; Jain, 2017a, 2017b; Ranganathan, Ganapathy and Jain, 2017; Ariga et al., 2018; Gupta, Ariga and Deogade, 2018; Anbu et al., 2019; Ashok and Ganapathy, 2019; Duraisamy et al., 2019; Varghese, Ramesh and Veeraiyan, 2019), this vast research experience has inspired us to research about the assessment of anxiety of dental treatments among dental students. The aim of this study is to determine the frequency of dental anxiety to perform dental procedures among dental students. It is very difficult to attend to patients when the dental care providers are under dental anxiety, therefore compromising the patients care.

\section{MATERIAL AND MIETHODS}

Study design and setting: This cross-sectional study was conducted in Saveetha Dental College and Hospital, Saveetha university, Chennai, to assess dental anxiety of dental treatment among undergraduate students (third years, final years and interns). The approval for this university setting study was obtained from the institutional review board.

Study subjects: A total of 140 students had participated in the study, among which 30 (21.43\%) were third years, $25(17.86 \%)$ were final years and the remaining 85 $(60.71 \%)$ were interns.

Questionnaire survey: Study questionnaire was conducted through Google Form application using the modified Moss and McManus (Moss and McManus, 1992) clinical anxiety questionnaire. It contained 13 questions from the original document in relation to the specific perceived sources of anxiety. Each question was assessed using a 4-point Likert scale from "not anxious," "slightly anxious," "fairly anxious" to "very anxious." For the purpose of analysis, responses were scored 1 for not anxious, 2 for slightly anxious, 3 for fairly anxious, and 4 for very anxious.

Statistical analysis: The collected data was validated, tabulated and analysed with Statistical Package for Social Sciences for Windows, version 23.0 (SPSS Inc., Chicago, IL, USA) and results were obtained. Descriptive statistics (frequency distribution, percentage and mean value) and inferential statistics (chi-square test) were done. P value $<0.05$ was considered statistically significant.

\section{RESULTS AND DISCUSSION}

Of the 140 respondents, 30 (21.43\%) were third years, $25(17.86 \%)$ were final years and the remaining 85 (60.71\%) were interns. [Figure 1]. A total of 57 (40.71\%) and 83 (59.29\%) of the dental students were males and females respectively. [Figure 2]. Female students rated all situations related to act of dental treatments as more anxiety provoking than the male students; Treating 
children (2.52 vs. 2.31), coping with uncooperative patients (2.50 vs. 2.19), administering local anesthesia (2.78 vs. 2.42), using high speed hand piece (2.97 vs. $2.35)$ and poor radiograph taking (2.60 vs 2.40 ). Using extraction forceps and doing root canal treatment in molars were the two top anxiety provoking situations among male students when compared to female students. [Figure 3].

Figure 1 : Bar graph shows number of respondents based on year of study. $\mathrm{X}$ axis represents the year of study. Y axis represents the number of respondents. $30(21.43 \%)$ of the respondents were third years, $25(17.86 \%)$ were final years and the remaining $85(60.71 \%)$ were interns.

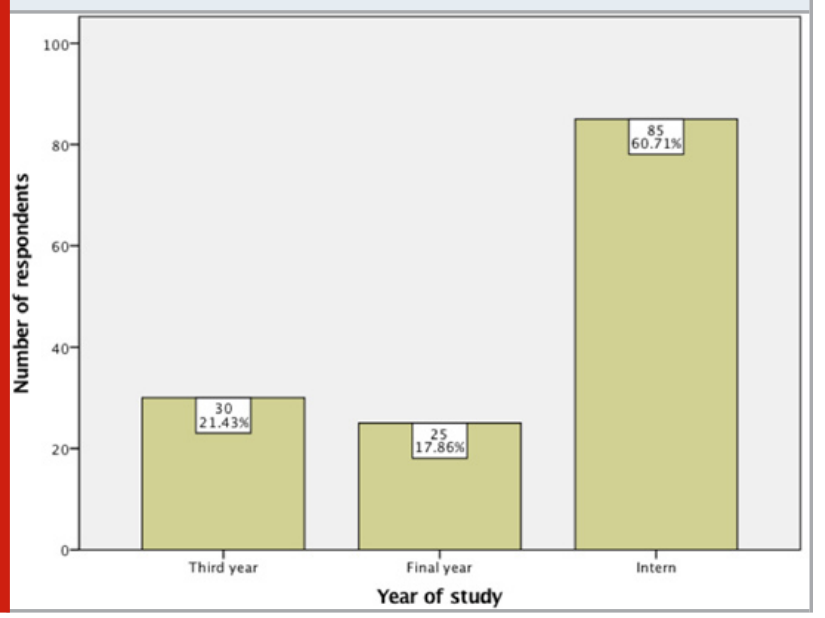

Figure 2 : Bar graph shows number of respondents based on gender of study population. $\mathrm{X}$ axis represents gender. $\mathrm{Y}$ axis represents the number of respondents. Males (blue) and females (green). 83 (59.29\%) of the respondents were females and 57 (40.71\%) were male respondents.

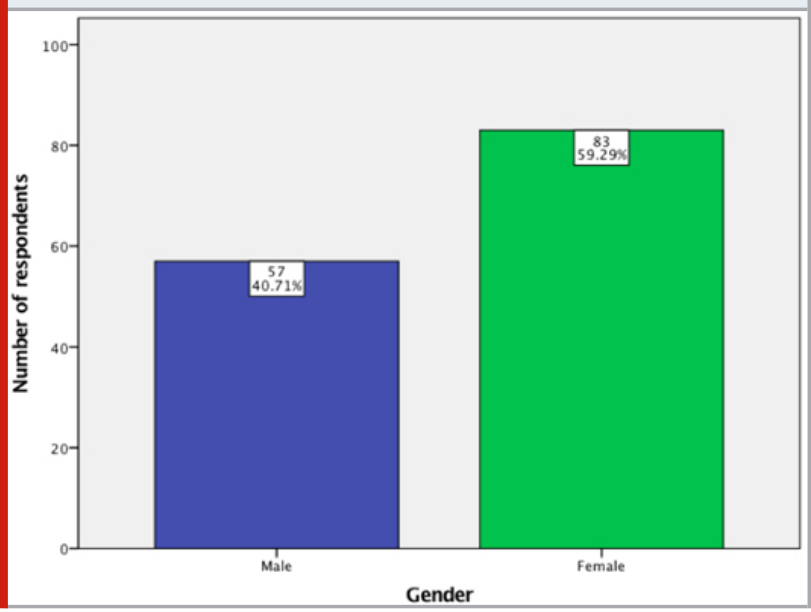

Assessment of deficiencies and error related situations among the participants revealed the following rating of males versus females on the anxiety provoking situations; Iatrogenic gingival trauma (2.63 vs. 2.44), inadvertently hurting patients (2.43 vs. 2.55), fear of patient's satisfaction with denture (2.52 vs. 2.56). Strikingly, male students expressed a greater tendency

to be anxious when accidentally exposed pulp tissue. Meanwhile, female students were more highly anxious about fracturing a tooth and extracting a wrong tooth when compared to male students. [Figure 4]. There was a statistically significant difference in mean score for using high speed hand piece with the female respondents scoring higher ( $p$ value $=0.000$ ). There was a statistically significant difference between both sexes with respect to fracturing a tooth ( $\mathrm{p}$ value $=0.02$ ) and accidental pulpal exposure $(p$ value $=0.004)$. [Table 1$]$.

Figure 3 : Bar graph shows frequency of dental anxiety based on act of treatment related situations. $\mathrm{X}$ axis represents the act of treatment related situations. $Y$ axis represents the frequency of dental anxiety based on mean value. Males (blue) and females (green). Among these treatments, females were more anxious than males for all of the procedures (treating children, coping with uncooperative patients, administering local anesthesia, using high speed hand piece, poor radiograph taking) except the use of extraction forceps and root canal treatment in molars.

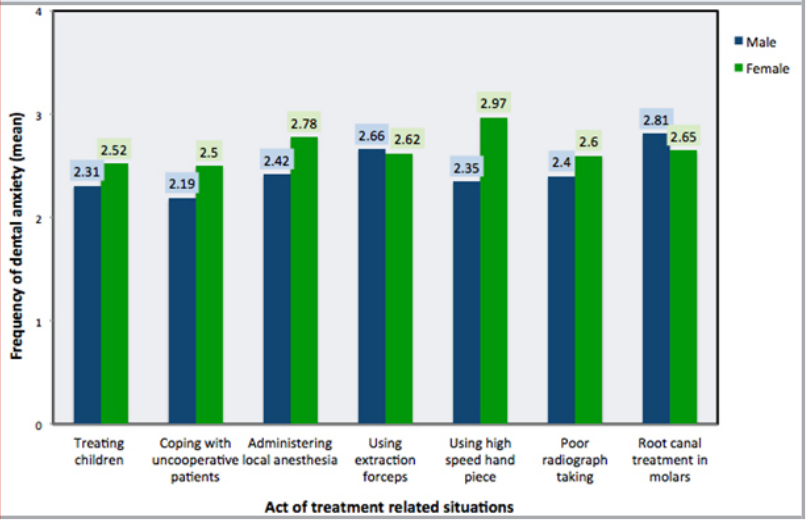

Figure 4 : Bar graph shows frequency of dental anxiety based on deficiencies and error related situations. $\mathrm{X}$ axis represents the deficiencies and error related situations. $\mathrm{Y}$ axis represents the frequency of dental anxiety based on mean value. Males (blue) and females (green). Among these treatments, females were more anxious than males for all of the procedures (fracturing a tooth, extracting wrong tooth, inadvertently hurting patients and fear of patients satisfaction with denture) except iatrogenic gingival trauma and accidental pulp exposure.

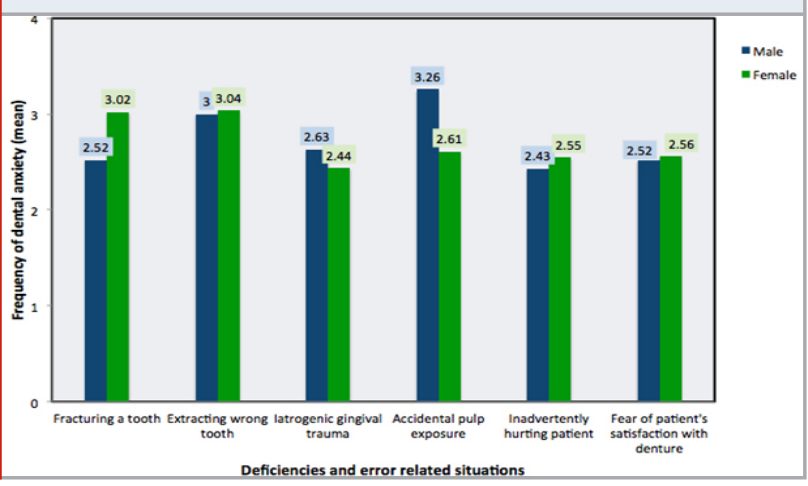


This cross-sectional study was to evaluate and assess the anxiety levels to dental procedures among students of Saveetha Dental College. Majority of the students rated deficiencies and error during treatment as more anxiety provoking situations as compared to act of treatment situations. According to male students, the top clinical anxiety provoking situations were accidental pulpal exposure and extracting the wrong tooth. Females voted most for fracturing teeth and extracting the wrong tooth. This study revealed that even dental students can suffer dental phobia during their course. This finding is similar to a study in Brazil, which found that 27.5\% of dental students experienced dental anxiety after encountering clinical practices (Serra-Negra et al., 2012). Similarly in Pakistan, a study revealed that dental students were afraid to perform dental treatments during their initial years of training (Bari, 2019). Stanford et al had compared the level of dental fear among students of dentistry, psychology and biology, among which dental students were least who elicited dental fear (Serra-Negra et al., 2012).

Table 1 . Shows the gender differences in anxiety provoking clinical situations among dental students

\begin{tabular}{|c|c|c|c|}
\hline $\begin{array}{l}\text { Anxiety } \\
\text { Provoking Situations }\end{array}$ & $\begin{array}{c}\text { Male } \\
\text { (mean } \\
\text { value) }\end{array}$ & $\begin{array}{c}\text { Female } \\
\text { (mean } \\
\text { value) }\end{array}$ & P value \\
\hline \multicolumn{4}{|c|}{ Act of treatment related situations } \\
\hline Treating children & 2.31 & 2.52 & 0.589 \\
\hline $\begin{array}{l}\text { Coping with uncooperative } \\
\text { patients }\end{array}$ & 2.19 & 2.5 & 0.285 \\
\hline Administering local anesthesia & 2.42 & 2.78 & 0.156 \\
\hline Using extraction forceps & 2.66 & 2.62 & 0.287 \\
\hline Using high speed hand piece & 2.35 & 2.97 & 0.000 \\
\hline Poor radiograph taking & 2.4 & 2.6 & 0.522 \\
\hline Root canal treatment in molars & 2.81 & 2.65 & 0.24 \\
\hline \multicolumn{4}{|c|}{ Deficiencies and error related situations } \\
\hline Fracturing a tooth & 2.52 & 3.02 & 0.02 \\
\hline Extracting wrong tooth & 3 & 3.04 & 0.961 \\
\hline Iatrogenic gingival trauma & 2.63 & 2.44 & 0.251 \\
\hline Accidental pulp exposure & 3.26 & 2.61 & 0.004 \\
\hline Inadvertently hurting patient & 2.43 & 2.55 & 0.884 \\
\hline $\begin{array}{l}\text { Fear of patient's } \\
\text { satisfaction with denture }\end{array}$ & 2.52 & 2.56 & 0.761 \\
\hline
\end{tabular}

In general, this present study reported that females had a greater phobia of dental treatments when compared to male students, corroborating with a study carried out by Ali et al (Ali et al., 2015). This trend could be attributed to the high number of male participants in the study. In addition to this, males frequently hide their emotion and keep their guard up. It is also evident that the female population tends to be more reactive towards specific stimuli such as needle prick, therefore accounts for more increase of anxiety than males. Nevertheless, females are relevantly said to commonly have traits of anxious and jealous (Lippa, 2010).

The results of this current study showed that, overall, the most feared dental procedure reported was fear of fracturing a tooth, extracting the wrong tooth and accidental pulpal exposure. Similar results have been demonstrated in a previous study where dental extractions was rated as the most scariest procedure, as perceived by Pakistani dental students (Ali et al., 2015) Fracturing a tooth during extraction may happen because of inadequate apical thrust or it could be associated with lack of confidence to do proper extraction forces. The prevalence of extracting wrong teeth among dental students in Otago was reported to be 13\% (Kieser and Herbison, 2000) and it is considered as a medical error with medico-legal complications (Lee, Curley and Smith, 2007).

The noted higher anxiety score among female students than male students in act of treatment related situations such as treating children, coping with uncooperative patients, administering local anesthesia, using high speed hand piece and inadvertently hurting patients may explained to why females pay to more attention to details thereby lessening their committal of medical error than males. This is in concordance with another similar study that reported the majority of females were associated with high levels of anxiety in relation to act of treatment related situations such as treating children and arresting post-operative bleeding. Both sexes in this study expressed more tendencies to be anxious when accidentally caused pulp exposure during dental procedures. Obarisiagbon et al also reported the same in his study, which can be explained by the poor prognosis when simple dental care has to change into endodontic procedure. High clinical anxiety provocation with use of the high speed hand piece may be contributory. Endodontic treatment is technique sensitive with limitation of mouth opening for prolonged periods and saliva as fluids. This gives clues to why students have low confidence and inexperience to do endodontic treatments (Obarisiagbon et al., 2013).

Our study was limited to a small sample size distribution within representation from one dental institution. Other shortcomings of this study include the prominence difference between both sexes of dental students in the study, which may affect the statistical analysis. There is a need for future studies with extensive larger scalestudy with richer clinical data in order to obtain more accuracy of the findings in association of different community-based investigations. The prevalence of anxiety among dental students in this study demonstrates early recognition and management strategies must be addressed among students to ensure positive influence in their clinical practice.

\section{CONCLUSION}

Within the limitations of this study, we can conclude that the majority of the students rated deficiencies 
and error during treatment as more anxiety provoking situations as compared to act of treatment situations. According to male students, the top clinical anxiety provoking situations were accidental pulpal exposure and extracting the wrong tooth. Females voted most for fracturing teeth and extracting the wrong tooth. Accidental pulpal exposure, fracturing teeth and using high speed hand piece significantly elevates anxiety levels in dental students.

\section{ACKNOWLEDGEMENTS}

The authors of this study would like to express their gratitude towards everyone who facilitated and enabled us to carry out this study successfully.

Authors Contributions: Nor Masitah Mohamed Shukri analysed, interpreted, tabulated data and wrote the manuscript. Dhanraj Ganapathy and Revathi Duraiswamy performed the validation, data design and critically revised the manuscript. Arthi Balasubramaniam revised the manuscript. All the three authors have equally contributed to the final manuscript.

Conflict of Interest: Authors have no conflict of interest to declare.

\section{REFERENCES}

Ali, S. et al. (2015) 'Self-reported anxiety of dental procedures among dental students and its relation to gender and level of education', Journal of Taibah University Medical Sciences, pp. 449-453. doi: 10.1016/j.jtumed.2015.06.002.

Anbu, R. T. et al. (2019) 'Comparison of the Efficacy of Three Different Bone Regeneration Materials: An Animal Study', European journal of dentistry, 13(1), pp. 22-28.

Ariga, P. et al. (2018) 'Determination of Correlation of Width of Maxillary Anterior Teeth using Extraoral and Intraoral Factors in Indian Population: A Systematic Review', World Journal of Dentistry, 9(1), pp. 68-75. Armfield, J. M., Stewart, J. F. and Spencer, A. J. (2007) 'The vicious cycle of dental fear: exploring the interplay between oral health, service utilization and dental fear', BMC oral health, 7, p. 1.

Ashok, V. and Ganapathy, D. (2019) 'A geometrical method to classify face forms', Journal of oral biology and craniofacial research, 9(3), pp. 232-235.

Bari, Y. A. (2019) 'Effectiveness of Dental Training in Terms of Anxiety Control Among Dental Students-A Quasi Experimental Study', Advances in Dentistry \&t Oral Health. doi: 10.19080/adoh.2019.10.555786.

Davidovich, E. et al. (2015) 'Levels of Stress among General Practitioners, Students and Specialists In Pediatric Dentistry during Dental Treatment', The Journal of clinical pediatric dentistry, 39(5), pp. 419422.

Duraisamy, R. et al. (2019) 'Compatibility of Nonoriginal Abutments With Implants: Evaluation of Microgap at the Implant-Abutment Interface, With Original and Nonoriginal Abutments', Implant dentistry, 28(3), pp. 289-295.

Eli, I. (1993) 'Dental anxiety: a cause for possible misdiagnosis of tooth vitality', International endodontic journal, 26(4), pp. 251-253.

Evaluation of Corrosive Behavior of Four Nickelchromium Alloys in Artificial Saliva by Cyclic Polarization Test:An in vitro Study' (2017) World Journal of Dentistry, 8(6), pp. 477-482.

Ganapathy, D. M., Kannan, A. and Venugopalan, S. (2017) 'Effect of Coated Surfaces influencing Screw Loosening in Implants: A Systematic Review and Meta-analysis', World Journal of Dentistry, 8(6), pp. 496-502.

Gupta, P., Ariga, P. and Deogade, S. C. (2018) 'Effect of Monopoly-coating Agent on the Surface Roughness of a Tissue Conditioner Subjected to Cleansing and Disinfection: A Contact Profilometric Study', Contemporary clinical dentistry, 9(Suppl 1), pp. S122S126.

Hall, N. and Edmondson, H. D. (1983) 'The aetiology and psychology of dental fear. A five-year study of the use of intravenous diazepam in its management', British Dental Journal, pp. 247-252. doi: 10.1038/ sj.bdj.4805053.

Jain, A. R. (2017a) 'Clinical and Functional Outcomes of Implant Prostheses in Fibula Free Flaps', World Journal of Dentistry, 8(3), pp. 171-176.

Jain, A. R. (2017b) 'Prevalence of Partial Edentulousness and Treatment needs in Rural Population of South India', World Journal of Dentistry, 8(3), pp. 213-217.

Kesim, S. et al. (2012) 'The relationship between periodontal disease severity and state-trait anxiety level', Journal of the Pakistan Medical Association, 62(12), pp. 1304-1308.

Kieser, J. and Herbison, P. (2000) 'Clinical anxieties among dental students', The New Zealand dental journal, 96(426), pp. 138-139.

Kleinknecht, R. A. et al. (1984) 'Factor analysis of the dental fear survey with cross-validation', Journal of the American Dental Association , 108(1), pp. 59-61.

Lee, J. S., Curley, A. W. and Smith, R. A. (2007) 'Prevention of Wrong-Site Tooth Extraction: Clinical Guidelines', Journal of Oral and Maxillofacial Surgery, pp. 1793-1799. doi: 10.1016/j.joms.2007.04.012.

Lippa, R. A. (2010) 'Gender Differences in Personality and Interests: When, Where, and Why?', Social and Personality Psychology Compass, pp. 1098-1110. doi: 10.1111/j.1751-9004.2010.00320.x.

Moss, F. and McManus, I. C. (1992) 'The anxieties of new clinical students', Medical education, 26(1), pp. 17-20.

Obarisiagbon, A. et al. (2013) 'Clinical anxiety among final year dental students: The trainers and students perspectives', Sahel Medical Journal. Medknow Publications, 16(2), p. 64. 
Pohjola, V. et al. (2009) 'Dental fear and subjective oral impacts among adults in Finland', European Journal of Oral Sciences, pp. 268-272. doi: 10.1111/j.16000722.2009.00631.x.

Qamar, K., Khan, N. S. and Bashir Kiani, M. R. (2015) 'Factors associated with stress among medical students', Journal of the Pakistan Medical Association, 65(7), pp. 753-755.

Ranganathan, H., Ganapathy, D. M. and Jain, A. R. (2017) 'Cervical and Incisal Marginal Discrepancy in Ceramic Laminate Veneering Materials: A SEM Analysis', Contemporary clinical dentistry, 8(2), pp. 272-278.

Serra-Negra, J. et al. (2012) 'Self-reported dental fear among dental students and their patients', International journal of environmental research and public health, 9(1), pp. 44-54.

Varghese, S. S., Ramesh, A. and Veeraiyan, D. N. (2019) 'Blended Module-Based Teaching in Biostatistics and Research Methodology: A Retrospective Study with Postgraduate Dental Students', Journal of dental education, 83(4), pp. 445-450.

Vermaire, J. H. et al. (2016) 'The burden of disease of dental anxiety: generic and disease-specific quality of life in patients with and without extreme levels of dental anxiety', European journal of oral sciences, 124(5), pp. 454-458. 